\title{
ВОПРОСЫ ЭФФЕКТИВНОСТИ ИСПОЛНИТЕЛЬНОГО ПРОИЗВОДСТВА В РОССИЙСКОЙ ФЕДЕРАЦИИ
}

\section{THE EFFECTIVENESS OF EXECUTIVE PROCEDURE IN THE RUSSIAN FEDERATION}

A. Yandarov

Summary. This article is devoted to the one of the most important elements of maintenance of economic stability and other legal objects, business and civil relations is due enforcement of judicial acts and other executive acts. This article is devoted to the analysis of contemporary executive proceedings in the Russian Federation. It is necessary to consider issues of effective enforcement of judicial acts and acts of other government and civil bodies.

Keywords: Federal Bailiffs Service, compulsory execution, bailiff, legal status, public service.
$\mathbf{M}$ инистерство экономического развития Российской Федерации называет ключевым фактором успешного процветания России - государственное управление, которое направлено на достижение стратегических целей и предотвращения экономических угроз. Вследствие чего, деятельность органов принудительного исполнения Российской Федерации как органы исполнительной власти, осуществляющие функции по обеспечению установленного порядка деятельности судов, исполнению судебных актов, актов других органов и должностных лиц, правоприменительные функции и функции по контролю и надзору в установленной сфере деятельности подвергается оценке ее эффективности [3]. В рамках оценки эффективности деятельности территориальных органов Федеральной службы судебных приставов (далее - ФССП) можно выделить следующие показатели: организация исполнительного производства, организационно-управленческая деятельность, отдельные направления деятельности, внешняя оценка деятельности.

Анализ правовых норм, регламентирующие принудительное исполнение в России показывает, что многие проблемы носят, в большей степени, экономический и социальный характер, чем юридический. Таким образом, вопросы экономической и социальной сферы в рамках исполнительного производства оказывают влияние (прямо или косвенно) на деятельность судебных приставов-исполнителей и являются наиболее ценными,
Яндаров Артур Аликович

Аспирант, Российская академия народного хозяйства и государственной службы при Президенте

Российской Федерации artur.yandarov@gmail.com

Аннотация. В статье рассматривается один из важнейших элементов поддержания стабильности экономики государства и иных субъектов права, предпринимательских и иных гражданско-правовых отношений — соответствующие исполнение судебных актов, актов других органов и должностных лиц. В статье анализируется современное состояние исполнительного производства в Российской Федерации, а также поднимаются вопросы обеспечения эффективного принудительного исполнения судебных актов, актов других органов и должностных лиц.

Ключевые слова: Федеральная служба судебных приставов, исполнительное производство, судебный пристав, правовой статус, государственная служба.

решая данные вопросы в рамках правовых механизмов конкретной юридической деятельности при отсутсвии прямого правового характера, появляется возможность что-либо существенно изменить.

Становится понятно, что в настоящее время состояние дел в рассматриваемом вопросе характеризуется недостаточным охватом экономических процессов, которые происходят в государстве, отсутствием четкой направленности на решение проблем исполнительного производства, недостаточным вниманием к социальным аспектам (менталитет, правосознание и т.д.).

В проекте Министерства Юстиции от 16 февраля 2011 года «Долгосрочная программа повышения эффективности исполнения судебных решений (2011-2020 годы) указывалось, что «исполнительное производство реализуется только в тех случаях, когда должник может и способен выполнить требования исполнительного документа» [1].

В данной ситуации необходимо обратить внимание именно на аспект, указанный выше, то есть на повышения гарантий жизнедеятельности граждан, которые относятся к социально-незащищенным категориях лиц, а также на их социальную защиту, данное обстоятельство обусловлено тем фактором, что социально-незащищенные граждане испытывают трудности в правовой защите. Улучшение эффективности исполнительного 
производства возможно, при условии учета экономических и социальных факторов. Необходимо указать, что право и экономика не находятся в связи соподчинения, они неразрывно связаны, дополняют и поддерживают друг друга.

Понимая и осознавая важность социальных факторов, мы приходим к пониманию, что в Российской Федерации, указанные факторы оказывают громадное воздействие на эффективность исполнительного производства. Складываются ситуации, когда гражданин думает, что судебное решение не будет исполнено по ряду причин (объективные и(или) субъективные), в таком случае он перестает прилагать усилия к добровольному исполнению обязательств, а к процедурам принудительного исполнения относится с явным пренебрежением. Причин такого явления разные - правовое воспитание, представление о государственных органах, в том числе и представление о деятельности ФССП как что-то негативное. В данном случае граждане не желают исполнять установки государственно-властного характера, «навязанные сверху» предписания и, таким образом, внутренне пытаются избежать всяческие взаимоотношения с судебными приставами-исполнителями.

Также к социальным факторам, которые, на наш взгляд, влияют на развитие исполнительного производства, относятся следующие:

1. высокий уровень установок о возможности неисполнения установленных правил поведения;

2. восприятие гражданами, что судебное решение не будет исполнено, данное обстоятельство, в свою очередь, подрывает доверие к органам принудительного исполнения;

3. недовольство граждан деятельностью государственных служащих, которое подогревается информационным фоном о коррупционности представителей власти.

Для преодоления такой ситуации, могут выступать следующие способы:

1. Создание благоприятных условий для деятельности судебных приставов-исполнителей. В данном случае идет речь о повышение мотивации в сфере оплаты труда, необходимо отметить, что выпускники юридических вузов рассматривают службу в ФССП, только как первую ступень в качестве получения опыта. Вторая причина такой мотивации - исключение коммерциализации деятельности судебного пристава-исполнителя. Также данный способ позволит повысить престиж ФССП, что напрямую влияет на повышение уровня уважения со стороны граждан и снижения правового нигилизма.
2. Формирование модели добровольного исполнения требований исполнительных документов, которая поможет решить в какой-то части проблему правового нигилизма. Прежде всего, очень важно транслировать социальные рекламы, совершать просветительскую деятельность. Тем самым в сознание граждан внедряется важность и целесообразность исполнения различных исполнительных документов, снижая уровень «правового скептицизма».

В наши дни мы наблюдаем, что цифровая эпоха перестроила все механизмы взаимодействия общества. Эффективным является и использование новых технологий не только в исполнительном производстве, но в государственном управлении в целом. Новые технологии изменили то, как люди общаются, воспринимают информацию, как мобильные технологии радикально трансформируют сферу услуг, интернет-ресурсы позволяют миллиардом людей взаимодействовать друг с другом в режиме реального времени. Информационные технологии становятся движущей силой, благодаря которым появились и появляются инновационные модели работы. Человечество постепенно «оцифровывается», а это значит, что границы между людьми стираются и отчуждение преодолевается. Каждый человек становится ячейкой глобальной сети, что дает ему новые возможности, которые высокие технологии открывают для человечества

Объем информации увеличивается, люди взаимодействуют друг с другом посредством цифровых средств коммуникации, образовываются инновационные модели работы, именно поэтому на современном этапе важно, чтобы в каждом предметном поле были выработаны принципы и подходы, которые бы смогли помочь в реализации внедрения информационных технологий в различные сферы деятельности. Допуская и заочно принимая грядущие изменения, необходимо учитывать тот факт, что многие традиционные системы обмена информации теряют свою актуальность, некогда успешные практики оказываются устаревшими. Мы ни в коем случае не говорим, что традиционные системы обесценены и не имеют смысла, они до сих пор очень значимы, но в процентном соотношении все сильнее уступают аналогичным технологическим (инновационным) системам. Важно увидеть и понять грядущие перемены, разглядеть направление эволюции новых технологий, сформировать и реализовать концепции и методы в рамках информационных систем. Именно основополагающие концепции и методы смогли бы обеспечить интегрированный взгляд по вопросам информационных систем и информационных технологий в рамках исполнительного производства. 
Как мы понимаем, внедрение одной мощной системы в пределах развития государственного управления не сможет решить задачи, которые ставятся в контексте информатизации. При таких обстоятельствах, необходимо сформировать и обеспечить выбор соответствующих систем для эффективной работы инфраструктуры. В последние годы стали особенно актуальны вопросы, связанные с экономической эффективностью создаваемых информационных систем. Такая тенденция происходит в условиях, когда мы наблюдаем рост решения проблем при использовании информационных технологий для обеспечения потребностей государства и общества в целом.

В настоящее время мы периодически отмечаем несоответствие возможностей государственных органов в области выполнения основных своих функций. «Процесс дигитализации» обещает большие перемены. Прежде всего, изменения будут касаться формы работы государственных органов в рамках выполнения своих функций, из чего можно заключить, что функции и возможности государственных организаций будут более эффективными, гибкими и надежными. Проектирование и модернизация современных корпоративных информационных систем является комплексным и сложным вопросом. Использование информационных технологий является важной составляющей с точки зрения преобразования деятельности государства в контексте электронного правительства. Ведущие государства мира в области электронного правительства реализуют проекты и методики электронного правительства. Соответственно, реализация проектов направлена на координацию и структурирование формы деятельности правительства и государственных учреждений с целью усовершенствовать их деятельности путем использования информационных технологий.

Государственные учреждения оказывают онлайн-услуги и предоставляют необходимую информацию посредством информационной сети в контексте транспортировки и доставки данных. Необходимо указать, что предоставление информации и оказание услуг традиционными методами происходит весьма успешно, цель, однако, заключается в оптимизации качества предоставляемых услуг. Главное преимущество онлайн-услуг является общедоступность в использовании всех преимуществ информационной сети, независимо от времени и места, главное, чтобы была возможность подключиться к сети.

Таким образом, решая проблему эффективности исполнительного производства только в рамках реформирования правовой системы невозможно достичь реальных результатов, так как источники проблемы выступают и иные (экономические и социальные) факторы. В соответствии с вышесказанным, формирование единой программы совершенствования исполнительного производства в Российской Федерации даст более положительную динамику с учетом указанных факторов, которые влияют на недостаточную эффективность исполнительного производства.

Практическая реализация исполнительного производства является важной гарантией в рамках реализации важных социальных вопросов жизнедеятельности. Именно поэтому многое зависит от эффективной работы судебных приставов-исполнителей, в данном случае эффективность означает правильно организованная работа, которая бы позволила систематизировать процесс исполнения судебных и иных актов.

С 1 января 2020 года начал действовать Федеральный закон «О службе в органах принудительного исполнения Российской Федерации и внесении изменений в отдельные законодательные акты Российской Федерации», который изменил статус ФССП, таким образом, ФССП превратился в полноценный «силовой орган». В настоящее время стали задумываться о вопросе внедрения частных судебных приставов. Данный вопрос затрагивался в обзоре бюджетных расходов Министерства финансов Российской Федерации касательно реализации функций и полномочий ФССП [2]. Так согласно обзору, «в целях оптимизации расходов федерального бюджета, а также повышения эффективности функционирования системы принудительного исполнения в целом представляется целесообразным рассмотреть вопрос постепенного (поэтапного) внедрения элементов частного исполнения» [3]. На первом этапе частные судебные приставы займутся взысканиями в пользу юридических лиц. Взыскание в пользу государственных органов и физических лиц останется за ФССП.

Как следует из обзора [2]:

1. деятельность ФССП в рамках принудительного исполнения судебных актов и актов других органов направлена на осуществление взысканий как в пользу государственных органов и государственных внебюджетных фондов $(68,7 \%$ от общего количества производств, или 15,1\% от общей суммы, подлежащей взысканию, в 2018 году), так и в пользу юридических (24,4\% от общего количества производств или 70,1\% от суммы, подлежащей взысканию, в 2018 году) и физических (5,1\% от общего количества производств или 12,5\% от общей суммы, подлежащей взысканию, в 2018 году) лиц;

2. по итогам 2018 года было окончено и прекращено 52,6 млн. производств (или 59,9\%), сумма по которым составила 4,4 трлн. рублей (или 
42,2\% от общей суммы, подлежащей взысканию), при этом в части производств в пользу государственных органов и государственных внебюджетных фондов - 0,8 трлн. рублей (или 53,0\% от общей суммы, подлежащей взысканию в пользу государственных органов и государственных внебюджетных фондов), в пользу юридических лиц - 3,1 трлн. рублей (или 42,7\% от общей суммы, подлежащей взысканию в пользу юридических лиц), в пользу физических лиц - 0,4 трлн. рублей (или 29,3\% от общей суммы, подлежащей взысканию в пользу физических лиц);

3. на одного судебного пристава-исполнителя в 2018 году в среднем приходилось 3,7 тыс. производств (из них по 2,5 тыс. производств взыскателями выступают государственные органы и государственные внебюджетные фонды, по 0,9 тыс. производств - юридические лица, по 0,2 тыс. производств - физические лица) или 435,9 млн. рублей суммы, подлежащей взысканию (из них 65,7 млн. рублей в пользу государственных органов и государственных внебюджетных фондов, 307,6 млн. рублей в пользу юридических лиц, 54,5 млн. рублей в пользу физических лиц); на реализацию функций и полномочий ФССП России из федерального бюджета в 2018 году в среднем на одного сотрудника направлялось 637,9 тыс. рублей.
Что наглядно демонстрирует существенную нагрузку на судебных приставов-исполнителей. Концепция создания института частных приставов звучат не первый год, и, в данном случае, предлагается для решения указанной выше проблемы. С такой инициативой выступают бизнес-сообщества и государственные органы. В октябре 2019 года Торгово-промышленная палата РФ (далее - ТПП) представила свой вариант законопроекта «О частных судебных исполнителях». ТПП предложила, чтобы работа частных приставов распространилась на исполнение решений по арбитражным делам и с участием организаций. Исходя из законопроекта, частные приставы смогут арестовывать имущество и счета должника, обращать на них взыскание, требовать освободить помещение. Законопроект направили в Министерство юстиции Российской Федерации. Однако Министерство юстиции Российской Федерации указало, что данный вопрос требует детальной проработки.

Мы согласны, что есть все предпосылки для модернизации законодательной базы, которая бы регулировала деятельность новых институтов и модели правового регулирования исполнительного производства. Вопросы повышения эффективности исполнительного производства является актуальным и их решение возможно при наличии концепций в теории исполнительного производства и наличии четкой государственной политики в сфере исполнительного производства.

\section{ЛИТЕРАТУРА}

1. Проект Долгосрочной программы повышения эффективности исполнения судебных решений (2011-2020 годы) — Электрон. дан. — Режим доступа: http://docs.pravo.ru/document/view/10963602 (дата обращения 20.11.2019).

2. 0бзор бюджетных расходов на реализацию функций и полномочий Федеральной службы судебных приставов- Электрон. дан. — Режим доступа: httрs:// storage.consultant.ru/ondb/attachments/202001/4/4smxfdjrs8joq-qs/OBR_FSSP_QRB.pdf (дата обращения 25.09.2019).

3. Федеральный закон от 01.10.2019 № 328-Ф3 «0 службе в органах принудительного исполнения Российской Федерации и внесении изменений в отельные законодательные акты Российской Федерации» // Собрание законодательства РФ от 07.10.2019, № 40, ст. 5488.

(с) Яндаров Артур Аликович ( artur.yandarov@gmail.com ).

Журнал «Современная наука: актуальные проблемы теории и практики» 